\title{
Model-Driven Architecture for Cloud Applications Development, A survey
}

\author{
Amar Ibrahim E.Sharaf Eldein \\ College of Graduate Studies, \\ Computer Science and Information Technology \\ Sudan University for science and technology \\ Khartoum, Sudan
}

\author{
Hany H. Ammar \\ Lane Department of Computer Science and \\ Electrical Engineering, \\ College of Engineering and Mineral Resources \\ West Virginia University \\ Morgantown, USA
}

\begin{abstract}
Model Driven Architecture and Cloud computing are among the most important paradigms in software service engineering now a days. As cloud computing continues to gain more activities, more issues and challenges for many systems with its dynamic usage are introduced. Model Driven Architecture (MDA) approach for development and maintenance becomes an evident choice for ensuring software solutions that are robust, flexible and agile for developing applications.

This paper aims to survey and analyze the research issues and challenges that have been emerging in cloud computing applications with a focus on using Model Driven architecture (MDA) development. We discuss the open research issues and highlight future research problems.
\end{abstract}

Keywords: MDA; cloud computing; application development; Design Driven Software; SaaS;

\section{INTRODUCTION}

Architecture models are helpful for modeling complex software systems structure and dynamics[1].The software architecture model facilitates cloud providers to smoothly interact with the environment with interfaces that are embedded in all types of objects. The development environment could be useful for supporting applications, since they enable analysis, and experimentation in an easy and seamless way[2].Models of software requirements, structure and behavior at different levels of abstraction help all stakeholders decide how the system mission should be accomplished and maintained[3].Models consist of three design elements: processing, data and connecting elements [4].

\section{Background of the Study}

Models are used to predict systems properties and to gain better understanding of the systems, since changes in some parts of it will affect the rest of a system. In addition models help to communicate system characteristics to various stakeholders. The models are developed as blueprints to implement the physical system, and to understand its behavior[16].

\subsection{Model Driven Architecture (MDA)}

In this section we define the important terms used in this paper.

\subsubsection{MDA Definitions}

Definition 1: The MDA is an Initiative proposed by the Object Management Group (OMG)as an open, vendor neutral, approach to software development which is characterized by the use of models as the primary artifacts for understanding, design, construction, deployment, operation, maintenance and modification of a system [17].

Definition 2: Is a software development approach where the models are used as prime artifacts throughout the process of software development. These models are defined at different levels of abstraction to represent various aspects of the system [18].

Definition 3: Is the Attribute Driven Design (ADD) method is an approach to defining a software architecture in which the design process is based on the software quality attribute requirements, follows a recursive process that decomposes a system or system element by applying architectural tactics and patterns that satisfy its driving requirements [18].

\subsubsection{MDA Models}

The models in MDA are abstracted at three different levels:-

1. CIM(Computation Independent Model): is a software independent business domain model that bridges the gap between business experts and system experts.

2. PIM(Platform Independent Model): specifies the functionality of the system independent of the technology that would be used for its implementation.

3. PSM(Platform Specific Model): specifies the system in terms of implementation constructs that are specific to the implementation technology. A single PIM can be transformed into one or more PSMs, each PSM being specific to the technology platform on which the system would finally be implement [18].

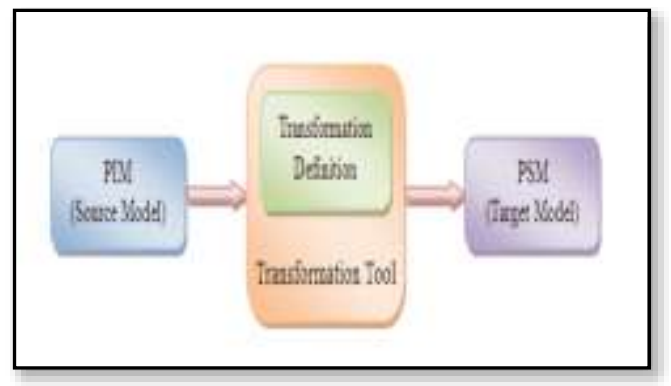

Figure 1.Transformation from PIM to PSM models [19].

The key to the success of MDA lies in automated or semi automated model to model and model to code transformations. The transformation tool executes a transformation definition that is specified for the purpose of transforming higher level, platform independent models into lower level platform specific models and finally into executable code[19]. 


\subsection{Cloud Computing}

Cloud computing appears to be a high technology; it has inherited legacy technology as well as new ideas on distributed systems. The computing power nowadays is needed for massive processing [5].The cloud architecture consists of three abstract layers: infrastructure, platform, and application.

Infrastructure is the lowest layer and is a means of providing processing, storage, networks and other fundamental computing resources as standardized services over the network.

Cloud computing regards infrastructure, platform, and software as services, which are made available as order based services in a pay as you go model to users [1].

The wide spectrum of available Clouds, such as those offered by Microsoft, Google, Amazon, HP, AT\&T, and IBM, provides a vibrant technical environment, where small and medium enterprises (SMEs) can create innovative solutions and evolve their existing services offers[2].

\subsubsection{Cloud Definitions}

Definition 1: "A Cloud is a type of parallel and distributed system consisting of a collection of inter connected and virtualized computers that are dynamically provisioned and presented as one or more unified computing resource(s) based on service level agreements established through negotiation between the service provider and consumers." The user data and software reside on the Internet, possibly in datacenters and clusters located in different countries, which reduces the role of personal computer to a "dumb terminal" to access cloud via Internet. Computing resources are owned and managed by a cloud service provider (CSP). Using virtualization techniques, these virtualized resources, such as hardware, platforms, or services, are dynamically allocated to scale on demand according to customers' needs. If a CSP fails to offer the demand, the CSP may outsource to other CSPs [6].

Definition 2:According to the IEEE computer society cloud computing is:"A paradigm in which information permanently stored in servers on internet and cached temporarily on clients that include desktops, entertainment centers, table computers, notebooks, wall computers handhelds, etc." so cloud computing provide every facility as a service. It provides infrastructure as a service, software as a service and platform as a service[7]. In other words is a source for the dynamic provisioning of computing services, typically supported by state of the art data centers containing groups of networked Virtual Machines[8].

\subsection{Objective}

The main objective of our survey is to identify and analyze the current published research on model driven architecture for cloud applications development. We aim at identifying current architecture solutions for achieving quality of services and utilizing features of cloud computing for building reliable applications.

\subsection{Organization}

The paper is structured as follows. Section 2 presents the research method and specify the research questions and contributions. Insection3, we present and discuss related work. In addition we disuses the results of comparing different MDA methodologies and identify open issues of research. Finally in Section4, we present our conclusions.

\section{RESEARCH METHOD}

\subsection{Research Questions and Contributions}

The goal of our survey is to answer research questions as below: -

(1) RQ1. What are the research issues and challenges that are evolving in SaaS research?
(2) RQ2. Why do we need model driven architectures (MDA) in cloud computing?

(3) RQ3: what are the important research problems related to using MDA in developing cloud computing applications?

\subsection{Search Steps}

To survey on area we follow the steps on figure below for published Researches:-

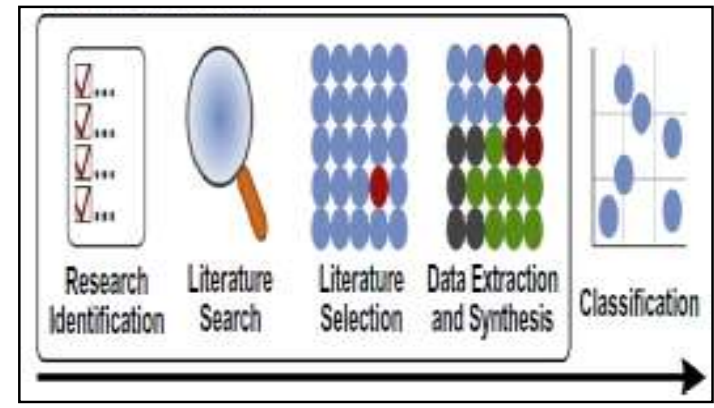

Figure 2. Steps of Research adapted from [47 ].

\section{Search Processes are:-}

\subsubsection{Search Identification}

The survey carries out a mapping study to find peer reviewed literature in order to classify and define topics related to software architectures development in cloud computing. From initially 95 papers, we selected 51 papers related to Model Driven Architecture, then analyzed and categorized of the papers using a taxonomy of 8 categories.

The search process covered journal articles and conference papers available in electronic databases, namely, IEEE Explorer and Elsevier. These databases were selected because they are available for access and known for including high quality publications in this area. The databases include a representative sample of the literature produced in the subject matter as pertinent to this research. We were interested in recent articles limited to articles published between 2005 and 2014

Table 1. Papers Publication Trend over Years

\begin{tabular}{|c|c|c|c|c|}
\hline \# & Year & $\begin{array}{l}\text { Cloud } \\
\text { Issues }\end{array}$ & $\begin{array}{c}\text { MDA } \\
\text { \&Cloud }\end{array}$ & $\begin{array}{c}\text { MDA } \\
\text { \&Cloud } \\
\text { Dev }\end{array}$ \\
\hline 1 & 2014 & 8 & 5 & 5 \\
\hline 2 & 2013 & 10 & 11 & 7 \\
\hline 3 & 2012 & 10 & 1 & 6 \\
\hline 4 & 2011 & 6 & 7 & 9 \\
\hline 5 & 2010 & 1 & 1 & 1 \\
\hline 6 & 2009 & - & 10 & - \\
\hline 7 & 2008 & - & 2 & - \\
\hline 8 & 2007 & - & 1 & - \\
\hline 9 & 2006 & - & 2 & - \\
\hline 10 & 2005 & - & 1 & - \\
\hline \multicolumn{2}{|c|}{ Total } & 35 & 41 & 28 \\
\hline
\end{tabular}

\subsubsection{Inclusion and Exclusion Criteria}

This paragraph answers RQ1: issues and challenges for Software as Services. Major researchers have been mainly focusing on issues related to security and privacy, infrastructure, data management and Interoperability across different service providers. Some issues and challenges that practitioners consider important are under studied such as software related to evolving technologies.

A Number of challenges can be identified for software systems developers and operators such as:- 
- Migrating Legacy Systems to the cloud: Such as modern the architecture to be more service oriented, data access layer, dealing with non functional requirements such as quality and using agile methods in the migration process.

- Software Evolution and Inconsistency in multi-tiered systems.

- Software Testing such as measuring the reliability of testing frameworks on the cloud.

- Standardizing Application: Cloud models and technologies are in their initial stage and are characterized by many critical issues which pose specific challenges from a software architecture perspective. SaaS model can be grouped into the following 10 factors: costs, security, availability, usability, implementation, ubiquity, flexibility, compatibility, analytics and best practices $[13,14]$.

- Mobile Cloud: With the increasing usage of mobile computing, exploiting its full potential is difficult due to its inherent problems such as resource scarcity, frequent disconnections, and mobility [9].Mobile devices are still resource poor. Battery life, weight, insufficient memory and heat dissipation limit the computational resources, and make mobile devices much more constrained [11].

- Software Development: The cloud platforms diversity and complexity pose challenges to the communication and coordination between software engineering and cloud providers during every stage in the software development process.

- Security and Privacy: Most papers aim to highlight the major challenges of security, privacy and trust issues in the existing cloud computing environments and help users recognize the tangible and intangible threats associated with their uses [12],

- Modeling and Simulation of Cloud Environments.

- Business to Cloud Services issues.

- Management issues.

Many of the above challenges are out of scope of our work, we focus on Model Driven Architecture for cloud applications development in next section.

\section{DISCUSSION AND RELATED WORK}

In this section we survey current work and determined different ways to compare achievements in development methodologies for cloud applications.

The Model Driven approach to the development of practical large scale applications is not an easy task [40].For example, one of the difficult problems is how to obtain models at the early phases of development to address the concerns of different stakeholders.

\subsection{Related Work}

In this section we present a taxonomy of eight categories to in order to classify the research work accordingly.

\subsubsection{Data Collection (Literature Selection)}

The benefits of using the MDD in cloud computing are discussed as follows:-

- To "reduce the primary software artifact's sensitivity to the inevitable changes that affect a software system" this result in a reduction of cost, the main selling argument of MDD approaches, Others see the main goal in an increase of abstraction which makes the design of complex systems easier. Since the abstraction from programming level issues makes the involvement of domain experts easier, by providing several different views on the same system [19].

- Improve the manageability of services without abandoning portability by create highly scalable applications and services using the providers' proprietary, also leading paradigm for efficiently managing services and applications in a highly automated manner.

- Cloud Computing technology evolution, incurs additional expenditure on part of the cloud service providers, as the applications in the cloud need to be reengineered with newer technologies, MDA approach is an asset which facilitates creation of good designs that easily cope with multiple implementation technologies and extended software lifetimes.

- Towards dynamic resource provisioning and define a cloud provisioning system based on mapping of functional and non functional tenancy requirements with appropriate resources [20].

- Improving the quality of cloud software services making them more robust, flexible and agile.

- Models Reflect separation of concerns by separating business functionality from implementation technology. While traditional software design and development processes create applications for deployment to a specific technology platform, MDA introduces higher levels of abstraction, enabling organizations to create models that are independent of any particular technology platform. The strength of MDA lies in the fact that it is based on widely used industry standards for visualizing, storing and exchanging software designs and models [16].

- Contemporary approach to software engineering that used to achieve greater portability of software in cloud.

- Migration applications across cloud provider for specific solutions.

Table 2. Gives taxonomy focus on eight category uses in cloud support by MDA

\begin{tabular}{|c|c|c|c|c|}
\hline \# & Category & Purpose & papers & $\begin{array}{c}\text { Papers } \\
\text { No }\end{array}$ \\
\hline 1 & Interoperability & $\begin{array}{l}\text { - The ability of computer systems to access, and } \\
\text { exchange resources with one or more other } \\
\text { performers and to use resources to accomplish its } \\
\text { performed activities according to expected } \\
\text { criteria. }\end{array}$ & $\begin{array}{c}{[21] ;[44] ;[46]} \\
;\end{array}$ & 3 \\
\hline 2 & Deployment & $\begin{array}{l}\text { - Help developers to be able design their software } \\
\text { systems for multiple clouds and for operators to } \\
\text { deploy and re-deploy these systems on various } \\
\text { clouds. }\end{array}$ & {$[22] ;[23],[43]$} & 3 \\
\hline 3 & Development & $\begin{array}{l}\text { - Development of software to mitigate } \\
\text { unfavorable effects of technology changes. }\end{array}$ & $\begin{array}{l}{[16] ;[24] ;} \\
{[25] ;[26] ;}\end{array}$ & 4 \\
\hline
\end{tabular}




\begin{tabular}{|c|c|c|c|c|}
\hline \# & Category & Purpose & papers & $\begin{array}{c}\text { Papers } \\
\text { No } \\
\end{array}$ \\
\hline 4 & Evolution & $\begin{array}{l}\text { - Used as a process of developing software as a } \\
\text { service initially on the basis of some } \\
\text { requirements, also to model requirements from } \\
\text { iterations to be evolving. } \\
\text { - Used to improve dynamic cloud service in } \\
\text { heuristic manner with healthiness validated. }\end{array}$ & $\begin{array}{c}\text { [27]; [42]; } \\
\text { [46]; }\end{array}$ & 3 \\
\hline \multirow[t]{4}{*}{5} & \multirow[t]{4}{*}{ Quality attribute } & $\begin{array}{l}\text { - Multi tenancy helps to determine the number of } \\
\text { resource provisioning to meet Service Level } \\
\text { Objectives. }\end{array}$ & {$[28] ;[29] ;[40]$} & 3 \\
\hline & & $\begin{array}{l}\text { - To run and mange multi-cloud systems, allows } \\
\text { cloud solution that optimize the performance, } \\
\text { availability and cost of the applications. }\end{array}$ & [46] & 1 \\
\hline & & - Achieves Reliability and scalability & [41] & 1 \\
\hline & & - Achieves Resource Scalability \&Provisioning & {$[16] ;[41] ;$} & 2 \\
\hline 6 & SOA & $\begin{array}{l}\text { Deliver services to either users or other services; } \\
\text { created to satisfy business goals, using web } \\
\text { services to handle communications. }\end{array}$ & {$[34] ;[35] ;[36]$} & 3 \\
\hline 7 & Migration & $\begin{array}{l}\text { Provide holistic view to inform decisions when } \\
\text { migrating to clouds. } \\
\text { - Benefits organizations to select efficient } \\
\text { transition architectures to increase productivity } \\
\text { and reduce complexity. }\end{array}$ & {$[37] ;[38] ;[39]$} & 3 \\
\hline 8 & Evaluation & $\begin{array}{l}\text { - To analyze the impact of cloud adoption to } \\
\text { identify potential risks and verify that the quality } \\
\text { requirements have been addressed in the design, } \\
\text { also to determine the robustness of systems. }\end{array}$ & [6] & 1 \\
\hline
\end{tabular}

\subsubsection{Data Filtering \&Analysis (Extraction \& Classification)}

Recently, many researchers presented in different studies approaches to use MDD to develop cloud applications.

Distributed data environment cannot be easily moved to any platform provider and may even cause problems to be used by a specific service (SaaS). It is almost impossible to move a service / environment between providers on the same level.

DaniloArdagnae.tal[6]implemented Model Driven Approach for the design and execution of applications on multiple Clouds (MODACLOUDS) that aims to support system developers and operators in exploiting multiple Clouds and in migrating systems from Cloud to Cloud as needed.

The work presented a framework and an Integrated Development Environment (IDE) used for developing and deploying applications in multi Clouds. In addition, a Decision Support System (DSS) is proposed to enable risk analysis for the selection of Cloud providers and for the evaluation of the Cloud adoption impact on internal business processes. Furthermore, the work offers a runtime environment for observing the system under execution and for enabling a feedback loop with the design environment that allows system developers to affect performance change and to redeploy applications on different Clouds on the long term.

However, there are many challenges such as Vendor Lock-in [42] to a specific vendor deployment.

The main concerns of cloud providers are how to deal with quality issues, the need for auto scaling mechanism for interoperability between different cloud platforms [42], and for developers to be able to design their software systems for multiple Clouds and for operators to be able to deploy and redeploy systems on various clouds. The portability of applications, data between Clouds, moving applications and data from Cloud to non-Cloud environments are not addressed. In addition Risk Management in the DSS uses only primitive tools and decision to support selecting and binding to a specific target cloud.

FrancescoMoscatoe.tal[40] Providers offer new different services to order customers' needs, Cloud Environments needs to define value added services (VAS) since users required increase complexity of services. The methodology uses Model driven Engineering and Model Transformation Techniques to analyze services, focused in using ontology to build modeling profiles that help to analyze complexity of systems, by developing open source platform that enables applications to negotiate cloud services requested by users via interface and targeted platform for developing multi cloud applications. One of the main goals is that of obtaining transparent, simple access to heterogeneous Cloud computing resources and to avoid locked in proprietary solutions. However, using ontology achieves interoperability but requires hard challenge.

Hugo \& Manu Sood[41]paper explores the interaction between service oriented engineering and model driven engineering. The work shows how these methodologies can benefit from each other. The paper introduces modeling as a Service (MaaS) to provide modeling that allows the deployment and on demand execution for services on the cloud. There are many applications of Maas such as distributed modeling tools to allow the specification, sharing of software models, Definition of modeling, availability of model transformation engines, improving scalability, model execution 
and evolution, solving tool interoperability problems, and distributed global model management.

However MDE models useful in the development of new SaaS applications could be used as part of service oriented architecture (SOA).There is no general agreement on the right set of models, languages, model transformations and software processes for the model driven development of SaaS systems. Furthermore, legacy system need to evolve and be adapted to be executed as service.

Mohammad Hamdaqa et al.[43]Presents a model driven approach for building cloud application solutions .The proposed approach presents a Reference model (Meta model) that facilitates cloud applications development from the design to implementation without depending on specific PaaS or IaaS components. This approach can be used by developers to better understand cloud applications independently of any specific cloud development environment. Moreover, the approach can improve flexibility by forcing developers to select a cloud vendor before porting the legacy application to the cloud.

Frey and Hassel bring,[44]presents a framework to facilitate the migration of legacy software to the cloud. The steps begin from existing legacy systems, extract the actual architecture then use a Meta-model to generate the target model to system migration. A reference model starts from the cloud platform to extract elements and vocabulary to create the cloud Metamodel.

The model needs to refine the syntax and create a platform independent modeling language for cloud applications.

There are several projects that aim at addressing challenges by providing solutions for provisioning, deployment, monitoring and adoption of cloud systems such as Modeling QoS constraints. In addition time consuming services are identified as a challenge for adaptive systems. Moreover handling failures during adaptation because multi cloud systems involves complex actions may consists of sub actions.

In addition, there is a lack of a systematic engineering process and tools supported by reusable architectural artifacts[45].

The authors Nicolas Ferry et al.[46] proposed Cloud Modeling language (CloudML) explain that model driven techniques and methods facilitating the specification of provisioning and deployment concerns of multi cloud systems, this will enables the continues evolution of system between design time and run time activities. Argue model driven is suitable for developing complex systems.

Table 3.Related work using MDA for cloud applications development.

\begin{tabular}{|c|c|c|c|c|c|}
\hline REF & Author/s & Approach & Advantages & Limitations & Domain \\
\hline [6] & $\begin{array}{c}\text { DaniloArdagnae.tal } \\
2012\end{array}$ & $\begin{array}{l}\text { MODACLOUDS, } \\
\text { model Driven } \\
\text { Approach for the design } \\
\text { and execution of } \\
\text { applications on multiple } \\
\text { Clouds. } \\
\text { Allows early definition } \\
\text { and assessment of } \\
\text { quality at design time. }\end{array}$ & $\begin{array}{l}\text { - Supporting system } \\
\text { developers and } \\
\text { operators in exploiting } \\
\text { multiple Clouds. } \\
\text { - Migrating applications } \\
\text { from Cloud to Cloud } \\
\text { (performance). } \\
\text { - Inform evolution } \\
\text { process to design time. }\end{array}$ & $\begin{array}{l}\text { - Vendor lock in on } \\
\text { cloud customer to } \\
\text { decide on adoption } \\
\text { model. } \\
\text { - Risk management } \\
\text { used primitive tools. } \\
\text { - Quality Assurance } \\
\text { need mechanisms to } \\
\text { be able deploy and } \\
\text { redeploy systems. }\end{array}$ & $\begin{array}{l}\text { Business } \\
\text { Application }\end{array}$ \\
\hline [40] & $\begin{array}{c}\text { Francesco } \\
\text { Moscatoe.tal } \\
2012\end{array}$ & $\begin{array}{l}\text { MOSAIC Ontology } \\
\text { methodology and } \\
\text { Framework, aims at } \\
\text { creating, promoting, } \\
\text { open source (API) and } \\
\text { platform for developing } \\
\text { multi cloud oriented } \\
\text { applications. } \\
\text { Frameworks enhance } \\
\text { modeling profile for } \\
\text { verification QoS of } \\
\text { cloud services. }\end{array}$ & $\begin{array}{l}\text { - Simple access to } \\
\text { heterogeneous } \\
\text { resources. } \\
\text { - Design interface for } \\
\text { users and implemented } \\
\text { existing services. } \\
\text { - Enable intelligent } \\
\text { service discovery. } \\
\text { (QoS) given for users to } \\
\text { avoid locked-in and for } \\
\text { providers to build on } \\
\text { demand services. }\end{array}$ & $\begin{array}{l}\text { Do not provide } \\
\text { approaches to model } \\
\text { and verify } \\
\text { dependability during } \\
\text { all phases of the life } \\
\text { cycle. } \\
\text { - Difficult to achieved } \\
\text { interoperability. }\end{array}$ & $\begin{array}{l}\text { Multi Agent } \\
\text { System }\end{array}$ \\
\hline [41] & $\begin{array}{c}\text { Hugo e.tal } \\
2010\end{array}$ & $\begin{array}{l}\text { Modeling as a Service } \\
\text { (MaaS) to provide } \\
\text { modeling and model } \\
\text { driven engineering } \\
\text { services from the cloud. }\end{array}$ & $\begin{array}{l}\text { - Using MDE for the } \\
\text { development of SaaS } \\
\text { applications. } \\
\text { - Using SaaS to deploy } \\
\text { modeling services in the } \\
\text { cloud. }\end{array}$ & $\begin{array}{l}\text { - No general agreement } \\
\text { on the right set of } \\
\text { models, languages, } \\
\text { model } \\
\text { transformations and } \\
\text { software processes } \\
\text { for the model driven } \\
\text { development of SaaS } \\
\text { systems. }\end{array}$ & $\begin{array}{l}\text { SaaS } \\
\text { application } \\
\text { (SOA) }\end{array}$ \\
\hline
\end{tabular}




\begin{tabular}{|c|c|c|c|c|c|}
\hline REF & Author/s & Approach & Advantages & Limitations & Domain \\
\hline [43] & $\begin{array}{c}\text { Mohammad } \\
\text { Hamdaqa et al } \\
2011\end{array}$ & $\begin{array}{l}\text { Defining A Reference } \\
\text { Model (Meta model)for } \\
\text { developing cloud } \\
\text { applications } \\
\text { environment. }\end{array}$ & $\begin{array}{l}\text { - Present Meta model } \\
\text { shows main cloud } \\
\text { vocabulary, design } \\
\text { elements, configuration } \\
\text { rules and semantic } \\
\text { interpretation. } \\
\text { - Facilitates cloud } \\
\text { application development } \\
\text { from the design to } \\
\text { implementation. }\end{array}$ & $\begin{array}{l}\text { - The lack of } \\
\text { standardization and } \\
\text { terminologies } \\
\text { challenges portability } \\
\text { and migration } \\
\text { between different } \\
\text { cloud environments. }\end{array}$ & $\begin{array}{c}\text { Cloud } \\
\text { Application }\end{array}$ \\
\hline [46] & $\begin{array}{c}\text { Nicolas Ferry et al } \\
2013\end{array}$ & $\begin{array}{l}\text { Cloud Modeling } \\
\text { language(CloudML) } \\
\text { aims at facilitating the } \\
\text { provisioning, } \\
\text { deployment, monitoring } \\
\text { and adaptation of multi } \\
\text { cloud systems. }\end{array}$ & $\begin{array}{l}\text { - Enables the evolution } \\
\text { of system between } \\
\text { design time and run } \\
\text { time activities. } \\
\text { - Enables developers to } \\
\text { work at higher level of } \\
\text { abstraction of cloud } \\
\text { concerns rather than } \\
\text { implementation details. }\end{array}$ & $\begin{array}{l}\text { - Model under } \\
\text { development and } \\
\text { many challenges } \\
\text { identified such as. } \\
\text { - Time consuming } \\
\text { development } \\
\text { activities for } \\
\text { adaptation. } \\
\text { - Techniques and } \\
\text { methods to prevent } \\
\text { failure. } \\
\text { - Data movements } \\
\text { from region to } \\
\text { another without } \\
\text { legal consequences. }\end{array}$ & $\begin{array}{l}\text { Multi Cloud } \\
\text { Systems }\end{array}$ \\
\hline
\end{tabular}

\subsection{Discussion and Result}

\subsubsection{Result Analysis}

In order to assess the benefits of MDA we provide a survey analysis on crosscutting concerns within the MDA context. We analyze MDA with respect to cloud applications development scenarios concerns. We first discuss the literature review, and outline literature selection based on cloud taxonomy issues stated in table (2).Furthermore, we compare different MDA used for cloud applications development to determine research challenges and limitations, as shown in table 3 .

\subsubsection{Open Issues}

We discuss some issues and challenges that need further research in developing cloud applications based on MDA as follows:

- There is no generic cloud software architecture for designing and building cloud applications [43], applications in cloud need to be reengineered with newer technologies [20] to distinguish the cloud development paradigm from the existing ones.

- Developers argue for the need for model driven techniques and supporting tools that facilitate the specification [46] of provisioning, deployment, monitoring and adaptation concerns at design time and their enactment at run time. The need to bind configuration management in order to minimize shortcomings[19].

- Need to build cloud applications that offer cloud providers for auto scaling mechanism for interoperability between clouds [6].

- The lack of standardization and common terminologies that challenges portability, also need to migrate application's components between cloud providers as needed [6].

- Quality of applications pose a need for developers to be able to design their applications and for operators to operate, monitor and assure performance change of cloud applications to be able to deploy and redeploy on multi Cloud environments.
The above described effort in the area of applications on clouds indicates that the topic still requires research on new programming abstractions, developing and presents best solutions. We believe that the work described in this paper be a part of an interesting approach in this concern.

\section{CONCLUSION}

This paper surveyed research work on using model driven approaches for cloud applications development.

We reviewed literatures of cloud computing with emphasis on Model Driven architecture. We covered the major methods, and summarized their features in Table 3. We also discussed several open research issues.

The result shows that most of methods focus on the main concept of model Driven Design to provide arguments that justify the effort of using these approaches that promise to reduce the overhead of developing, configuring, deploying and maintaining cloud applications.

We believe our work provide a better understanding of principles and challenges of developing applications in clouds to help developers, architects and researchers to use, support, evaluate and predict different methods and techniques.

\section{ACKNOWLEDGMENTS}

Our thanks to Quarter National Research Fund (QNRF) under the National Priorities Research Program (NPRP) grant \# [7662-2-247] (a member of Quarter Foundation) for funded this research.

Also we would acknowledge colleagues whom help for gathered papers from digital resources and the anonymous reviewers for their comments that have greatly helped to improve the quality of this paper.

\section{REFERENCES}


[1] Chengzhang Peng, Zejun Jiang, Building a Cloud Storage Service System, Elsevier, Procedia Environmental Sciences 10 ( 2011 ) $691-696$.

[2] Katia Vilae.tal Model-driven adaptation of question answering systems for ambient intelligence by integrating restricted-domain knowledge/ Elsevier,Volume 4, 2011, Pages 1650-1659.

[3] Tom Mens, Pieter Van Gorp, A Taxonomy of Model Transformation, ELSEVIER, Electronic Notes in Theoretical Computer Science 152 (2006) 125-142.

[4] BasGraaf,Model-Driven Evolution of Software Architectures, thesis, 2007.

[5] Bhaskar Prasad Rimal, Eunmi Choi, Ian Lumb, taxonomy, issues for cloud computing Ecosystems springer, 2010.

[6] DaniloArdagna\&e.tal ,MODACLOUDS: A ModelDriven Approach for the Design and Execution of Applications on Multiple Clouds, IEEE, 2012.

[7] National Institute of Standard and US Department of Commerce Technology, "The NIST Definition of Cloud

Computing,"2012.http://csrc.nist.gov/publications/nist pubs/800-145/SP800-145.pdf ,1=( Emerging Issues \& Challenges in Cloud Computing- A Hybrid Approach).

[8] Fa-Chang e.tal , The Impact of Cloud Computing Technology on Legal Infrastructure within InternetFocusing on the Protection of Information Privacy, International Workshop on Information and Electronics Engineering, 2012.

[9] Niroshinie Fernando \&e.tal, Mobile cloud computing: A survey, 24th DAAAM International Symposium on Intelligent Manufacturing and Automation, 2014.

[10] AleksandarBahtovski\&e.tal, Cloudlet Challenges, 24th DAAAM International Symposium on Intelligent Manufacturing and Automation, 2014.

[11] Xiao Ma, Yong Cui, Ivan Stojmenovic, Energy Efficiency on Location Based Applications in Mobile Cloud Computing: A Survey The 9th International Conference on Mobile Web Information Systems, Procedia Computer Science 10 ( 2012 ) 577 - 584.

[12] Dawei Sun e.tal, Surveying and Analyzing Security, Privacy and Trust Issues in Cloud Computing Environments, Elsevier, 2011.

[13] Cloud Computing the New Frontier of Internet Computing, Published by the IEEE Computer Society, 2010.

[14] Björn Johansson, Pedro Ruivo, Exploring Factors for Adopting ERP as SaaS, Elsevier, 2013.

[15] Karakostas\&Zorgios, Model-Driven Service Engineering, IGI Global, 2008.

[16] Ritu Sharma and Manu Sood, ENHANCING CLOUD SAAS DEVELOPMENT WITH MODEL DRIVEN ARCHITECTURE, International Journal on Cloud Computing: Services and Architecture(IJCCSA),Vol.1, No.3, November 2011.

[17] Attribute-Driven Design (ADD), Version 2.0, RobWojciketal, November 2006.

[18] AnnekeKleppe, Jos Warmer, WimBast: MDA Explained: The Model Driven Architecture: Practice and Promise. Pearson Education, 2003.

[19] R. Gitzel et al, Using established Web Engineering knowledge in model-driven approaches, ELSEVIER, 2007.
[20] AtulGohad and e.tal, Model driven provisioning in multi-tenant clouds, Service Research and Innovation Institute Global Conference, 2012.

[21] Towards Model Driven Tool Interoperability: Bridging Eclipse and Microsoft Modeling Tool.

[22] Integrating Configuration Management with Model driven Cloud Management based on TOSCA Towards Model Driven Tool Interoperability.

[23] Hugo Bruneli'ere, Jordi Cabot and Fr'ed'ericJouault, Combining Model-Driven Engineering and Cloud Computing, Modeling, Design, and Analysis for the Service Cloud - MDA4ServiceCloud'10: Workshop's 4th edition (co-located with the 6th European Conference on Modeling Foundations and Applications - ECMFA ,2010.

[24] Abderrahman Matoussi R'egineLaleau,A Survey of Non-Functional Requirements in Software Development Process, 2008.

[25] Junichi Suzuki e.tal, Model-Driven Integration for a Service Placement Optimizer in a Sustainable Cloud of Clouds, 2012.

[26] Ardagna, D. e.tal,A Model-Driven Approach for the Design and Execution of Applications on Multiple Clouds,IEEE,2012.

[27] Dr Kevin Chalmers ,Evolution Feature Oriented Model Driven Product Line Engineering Approach for Synergistic and Dynamic Service Evolution in Clouds,2013.

[28] AA Falasi, MA Serhani, R Dssouli, A Model for Multilevels SLA Monitoring in Federated Cloud Environment,2013.

[29] FunmiladeFaniyi et al., A Dynamic Data-Driven Simulation Approach for Preventing Service Level Agreement Violations in Cloud Federation, International Conference on Computational Science ,Elsevier , 2012.

[30] Anders Henrikssonet\& Uwe Aßman, Improving Software Quality in Safety-Critical Applications by Model-Driven Verification, Electronic Notes in Theoretical Computer Science 133, Elsevier, 2005.

[31] Petra Marešová\&KateřinaPůžová, Application of the Cost Benefit Analysis method in Cloud Computing in the Czech Republic, WCBEM, Elsevier, 2014.

[32] Danny Thebeau II e. tal, Improving cyber resiliency of cloud application services by applying Software Behavior Encryption (SBE), Conference on Systems Engineering Research, Elsevier, 2014.

[33] R. Gitzel et al, Using established Web Engineering knowledge in model-driven approaches, ELSEVIER, 2007.

[34] Catalina Martínez-Costa et al, model-driven approach for representing clinical archetypes for Semantic Web environments, ELSEVIER, Journal of Biomedical Informatics, 2009.

[35] Mohsen MohammadiandMuriati Mukhtar, A Review of SOA Modeling Approaches for Enterprise Information Systems, The 4th International Conference on Electrical Engineering and Informatics, 2013.

[36] J. Knodel et al., An Efficient Migration to Model-driven Development (MDD), Elsevier, 2005.

[37] Mark Harman et al, Cloud engineering is Search Based Software Engineering too, The Journal of Systems and Software 86 (2013) 2225- 2241, Elsevier , 2013.

[38] Imran Khan et al, Migrating To The Cloud: Lessons And Limitations Of 'Traditional' IS Success Models, 
Conference on Systems Engineering Research (CSER'13),Elsevier, 2013.

[39] AtifFarid Mohammad e.tal, Software Evolution as SaaS: Evolution of Intelligent Design in Cloud, Elsevier, Procedia Computer Science 19, 486 - 493, 2013.

[40] FRANCESCO MOSCATO_AND B. DI MARTINO AND R. AVERSA, ENABLING MODEL DRIVEN ENGINEERING OF CLOUD SERVICES BY USING MOSAIC ONTOLOGY, Scalable Computing: Practice and Experience, Volume 13, Number 1, pp. 29-44. http://www.scpe.org, 2012.

[41] Hugo Bruneli`ere e tal., Combining Model-Driven Engineering and Cloud Computing published in "Modeling, Design, and Analysis for the Service Cloud - MDA4ServiceCloud'10:Workshop's 4th edition (colocated with the 6th European Conference on Modelling Foundations and Applications - ECMFA, 2010.

[42] Tsaie.tal. ,Service Oriented Cloud Computing Architecture, inITNG10,7th International conference on Information Technology: New Generations, pages 684-689, 2010.

[43] HamdaqaM., Livogiannis T. and Tahvildari L., A Reference Model for Developing Cloud Applications, 1st International Conference on Cloud Computing and Service Science, pages 98-103, 2011.

[44] Frey and Hasselbring, Model Based Migration of Legacy Software Systems into the cloud: The Cloud MIG approach ,12th Workshop Software Reengineering ,pages 1-2, 2010.

[45] Liang-Jie Zhang; T.J. Watson Res, Architecture Driven Variation analysis for Design Cloud Applications, IEEE, 2009

[46] Nicolas Ferry, Alessandro Rossini, Franck Chauvel, Brice Morin, Arnor Solberg, Towards model-driven provisioning, deployment, monitoring, and adaptation of multi-cloud systems, Sixth International Conference on Cloud Computing, IEEE, 2013.

[47] Maria Leitner, Stefanie Rinderle-Ma, A systematic review on security in Process-Aware Information Systems - Constitution, challenges, and future directions, Elsevier, Information and Software Technology 56 (2014) 273-293.

\section{AUTHRORS BIOGRAPHIEES}

Amar Ibrahim E.Sharaf B. Sc and M.Sc both in Computer science, Sudan. He is IT manager, College of Computer Studies-Khartoum at National Ribat University, also work as a lecturer and supervision of under graduate projects since 2008 He was worked as Software Engineer from 2004 to 2006 on software Requirement Specification, analyzing various companies systems. During 2007 to 2013 work as par timer in Islamic Research Studies center (CSICW) responsible for IT solutions and technical support. Currently, he is PHD student at Sudan University of Science and Technology, College of Computer Science and Information Technology (SUST), my research interests in Software Architecture and Cloud Computing.

Hany H. Ammar BSEE, BS Physics, MSEE, and PhD EE, is a Professor of Computer Engineering in the Lane Computer Science and Electrical Engineering department at West Virginia University. He has published over 170 articles in prestigious international journals and conference proceedings. $\mathrm{He}$ is currently the Editor in Chief of the Communications of the Arab Computer Society On-Line Magazine. He is serving and has served as the Lead Principal Investigator in the projects funded by the Qatar National Research Fund under the National Priorities Research Program. In 2010 he was awarded a Fulbright Specialist Scholar Award in Information Technology funded by the US State Department - Bureau of Education and Cultural Affairs. He has been the Principal Investigator on a number of research projects on Software Risk Assessment and Software Architecture Metrics funded by NASA and NSF, and projects on Automated Identification Systems funded by NIJ and NSF. He has been teaching in the areas of Software Engineering and Computer Architecture since 1987. In 2004, he co-authored a book entitled Pattern-Oriented Analysis and Design: Composing Patterns to Design Software Systems, Addison-Wesley. In 2006, he co-authored a book entitled Software Engineering: Technical, Organizational and Economic Aspects, an Arabic Textbook. 